\title{
Preparation and properties of new elastomeric systems containing alternative fillers
}

\author{
Darina Ondrušová ${ }^{1,{ }^{*}}$, Ivan $_{\text {Labaj }}{ }^{1}$, Mariana Pajtášová ${ }^{1}$, and Juliana Vršková $^{1}$ \\ ${ }^{1}$ Alexander Dubček Universityof Trenčín, Faculty of Industrial Technologies in Púchov, I. Krasku \\ 941/30, 02001 Púchov, Slovak Republic
}

\begin{abstract}
The present paper deals with a preparation of new elastomeric compounds containing two kinds of alternative additives based on wastes from glass production and energetics. Named alternative fillers were mixed into rubber compounds asa replacement of commonly used fillers - carbon black and silica. Rheological properties, vulcanization characteristics as well as hardness and rebound resilience of vulcanizates, which are important parameters for their industrial application, have been studied in the new prepared elastomeric systems. The resulting vulcanizates containing alternative fillers exhibit improved properties, in particular low rolling resistance and high rebound resilience, while maintaining optimal hardness values. Used raw material substitution can also bring significant environmental and economic effects.
\end{abstract}

Keywords: rubber blend, vulcanizate, alternative filler, hardness, rebound resilience

\section{Introduction}

Most industrial products carry with them the creation of a byproduct or waste from production. By-products and wastes are often accumulate, thus becoming a burden for company. Often, waste disposal is economically demanding, and businesses try to reuse it, whether in primary production or in sales as a secondary raw material for other industries. As a secondary raw material, waste can become an alternative filler in the rubber industry. Not all waste or by-products can be used as alternative fillers. Especially inorganic materials and their application of into organic elastomers is one of the ways to improve up of physical and mechanical properties of elastomers specifically hardness, tensile straight, modulus [1]. Composite materials show generally better properties than pure and homogeneous materials. The positive changes have been observed at very low concentration of inorganic mineral component in polymers $[1,2]$. In addition to improving the properties of the resulting elastomer in the case of the application of alternative waste-based fillers, the low cost of the resulting product and the greening of production are also of great benefit. The best alternative is the possibility to fully replace commonly used filler with maintaining (or improving) the required products properties and the connected reduction in production costs. Article deals

\footnotetext{
* Corresponding author: darina.ondrusova@fpt.tnuni.sk

Reviewers: Ksawery Szykiedans, Ján Vavro Jr.
} 
with the preparation of elastomeric blends containing two types of alternative fillers and study of their properties. The first alternative filler (GWI) used in present experiments comes from the weighing process of raw materials in glass production, where creates the waste in a sludge form. The other type (ENERGO) arises as a byproduct in the flue gas desulphurization process in energetics.

\section{Materials and methods}

\subsection{Preparation of rubber blends with alternative fillers content}

A natural rubber grade SMR 10 has been used as the elastomeric matrix for the preparation of elastomeric blends, which, in addition to its biodegradability, has many other excellent complex properties. Alternative fillers (ENERGO, GWI) were dried to constant weight before adding to the mixture, and the alternative filler from glass industry (GWI) was grinded. They were then applied into elastomeric compounds as a replacement of the commonly used fillers (silica and carbon black). Percentual content of alternative fillers in rubber blends is given in Table 1. The elastomeric blends were prepared by two-step mixing at $90^{\circ} \mathrm{C}$ in a Plastograf Bradender laboratory mixer. After each step of mixing process was performed additional homogenizing the mixture on a laboratory two-roll mill, and the blends left to stand at room temperature for 24 hours $[3,4]$.

Table 1. Content of alternative fillers in prepared rubber blends

\begin{tabular}{|c|c|c|}
\hline & \multicolumn{2}{|c|}{ Content of alternative fillers in blend (wt.\%) } \\
\hline Sample & GWI & ENERGO \\
\hline Sample 1 & 13 & 26 \\
\hline Sample 2 & 16 & 25 \\
\hline Sample 3 & 22 & 16 \\
\hline Sample 4 & 28 & 11 \\
\hline Sample 5 & 30 & 3 \\
\hline
\end{tabular}

ENERGO - alternative filler from energetics, GWI - alternatie filler from glass industry

\subsection{Study of rheology and curing properties of elastomeric blends}

The properties of prepared elastomeric blends were studied in specialized laboratories at the Faculty of Industrial Technologies in Púchov. Rheological properties as minimum and maximum torque and curing characteristics - optimal cure time $\left(t_{c 90}\right)$ and scorch time $\left(t_{502}\right)$ were measured using Rubber Process Analyzer RPA 2000, at the temperature of $150^{\circ} \mathrm{C}$ during $15 \mathrm{~min}$. after determination of rheological properties, the vulcanization process was carried out using LabEcon 600 curing pneumatic press.

\subsection{Determination of hardness of vulcanizates}

Determination of hardness of prepared vulcanized rubber blends containing alternative fillers was carried out using hardness tester with IRHD scale. Hardness of vulcanizates was measured by hardness tester IRHD according to STN [5]. Measured values of each prepared blends are given in Table 3 and graphically processed in Fig. 3. 


\subsection{Determination of rebound resilience of vulcanizates}

Measurement of rebound resilience of prepared vulcanizates was caried out using apparatus Polymertest [6]. Measured values of rebound resilience are given in Table 4. In the Fig. 4 are graphically processed measured values of rebound resilience.

\section{Results and discussion}

In the results and discussion there are summarized the results of curing properties determination of prepared rubber blends and measurements of hardness and rebound resilience of final elastomeric vulcanizates containing the alternative fillers.

\subsection{Rheology and Curing properties}

Measured values of rheological properties of prepared blends with content of alternative fillers are given in Table 2. First described properties are the minimal and maximal torque. Minimal torque is the lowest value of torque indicated on the vulcanization curve, equal to viscosity of the compound heated to vulcanization temperature. This torque value characterizes the compound stiffness [7].

Table 2. Curing properties of prepared blends with alternative fillers

\begin{tabular}{|c|c|c|c|c|}
\cline { 2 - 5 } \multicolumn{1}{c|}{} & \multicolumn{4}{|c|}{ Curing properties } \\
\hline Sample & $\begin{array}{c}\text { Minimum torque } \\
\mathrm{M}_{\mathrm{L}}(\mathrm{dNm})\end{array}$ & $\begin{array}{c}\text { Maximum torque } \\
\mathrm{M}_{\mathrm{H}}(\mathrm{dNm})\end{array}$ & $\begin{array}{c}\text { Scorch time } \mathrm{t}_{\mathrm{s} 02} \\
(\mathrm{~min})\end{array}$ & $\begin{array}{c}\text { Optimal curing } \\
\text { time } \\
\mathrm{t}_{\mathrm{c} 90}(\mathrm{~min})\end{array}$ \\
\hline Sample 1 & 0.83 & 11.98 & 2.53 & 7.14 \\
\hline Sample 2 & 1.09 & 15.95 & 3.83 & 7.71 \\
\hline Sample 3 & 0.80 & 17.76 & 2.48 & 7.73 \\
\hline Sample 4 & 1.45 & 16.81 & 4.82 & 9.38 \\
\hline Sample 5 & 1.10 & 11.23 & 4.81 & 10.21 \\
\hline
\end{tabular}

From results of values of minimal torque it can be seen, that it is not possible to clearly determined the effect (increasing or decreasing character) of alternative fillers in rubber blends. Value of minimal torque $\left(\mathrm{M}_{\mathrm{L}}\right)$ was increased in the case of Sample 2, but Sample 3 showed an decrease again. Maximum value of minimal torque showed Sample $4(1.45 \mathrm{dNm})$.

Maximum torque is the highest value of torque indicated on the vulcanization curve, equal to the value of the vulcanized compound shear modulus at the given temperature. This torque value characterizes the vulcanizate stiffness at the end of vulcanization process [7].

When evaluating the maximum torque results, it is possible to see the dependence on the quantity of alternative fillers. With increasing the content of alternative filler from glass industry in rubber blends the value of maximum torque $\left(\mathrm{M}_{\mathrm{H}}\right)$ increased up to Sample 3. It is possible to assume, that Sample 3 contains optimal ratio of alternative fillers for reached maximal value of maximum torque. Further increase of content of alternative filler GWI in blend (Sample 4) led to decrease of maximum torque values. Named effect is visible also in the case of Sample 5. Increasing the value of maximum torque can be attributed directly to alternative filler GWI. Using the high content of alternative filler GWI (Sample 4), this filler 
prevents formation of bonds in curing process. In Sample 5, which contained maximal amount of alternative filler GWI, the same effect as in Sample 1 can be observed.

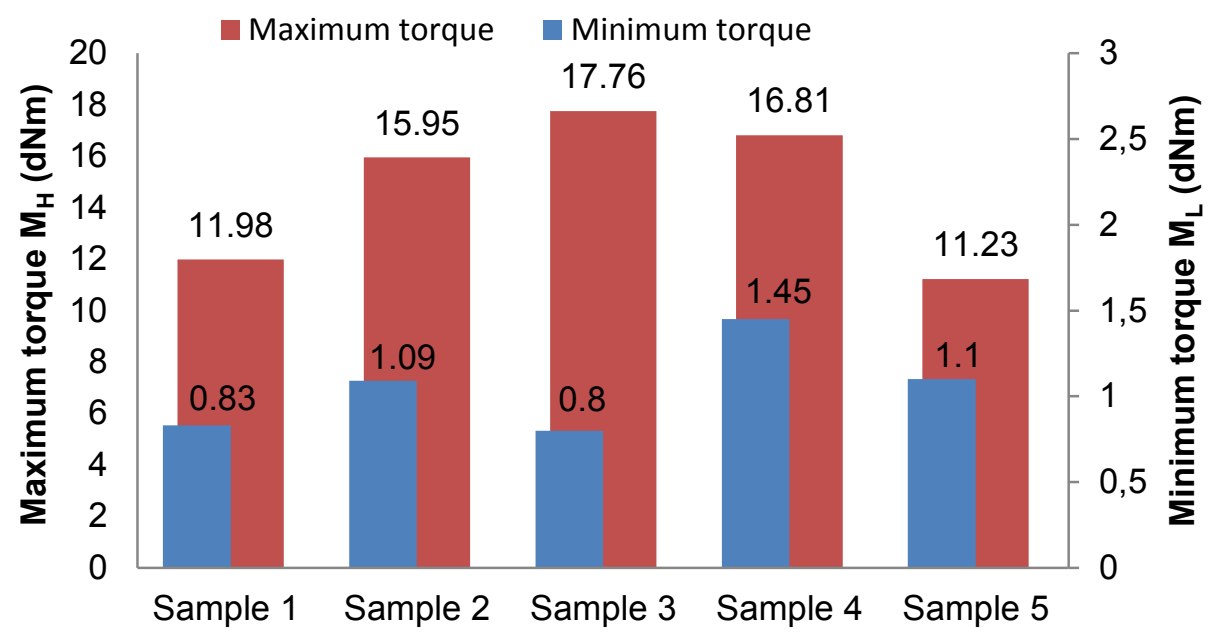

Fig. 1. Values of maximal and minimal torque of rubber blends

Scorch time is the time required at a specified temperature (or heat history) for a rubber compound to form incipient crosslinks. When a scorch point is reached after a compound is exposed to a given heat history from factory processing, the compound cannot be processed further by extruding, calendering, etc. Therefore, scorch measurement is very important in determining whether a given rubber compound can be processed in a particular operation [8].

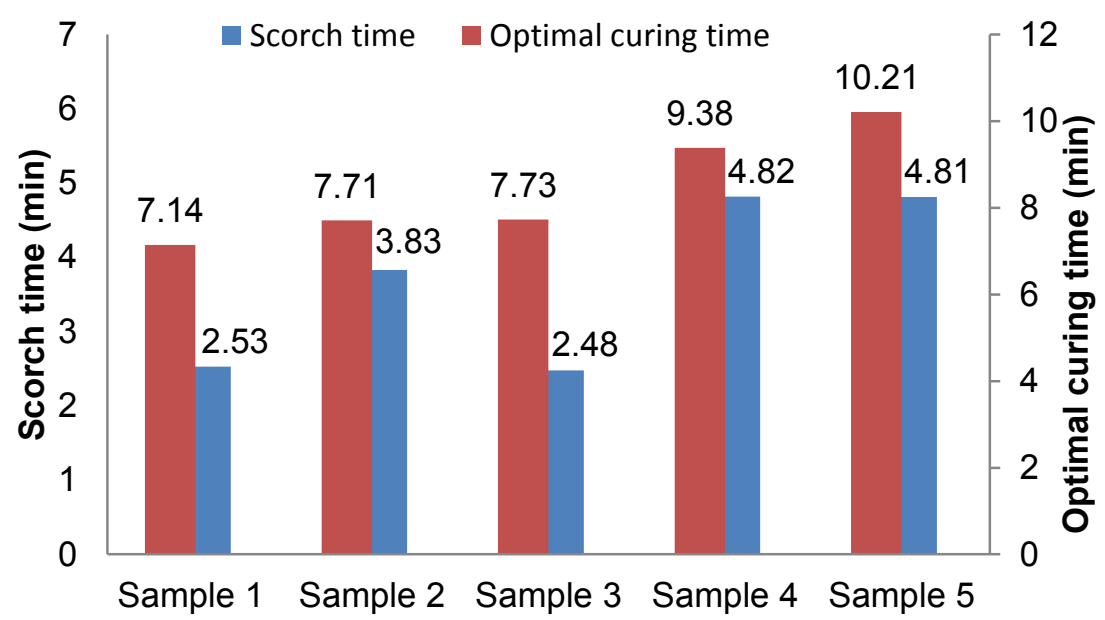

Fig. 2. Scorch time and optimal curing time values of rubber blends

With decreasing content of alternative filler ENERGO increased the value of scorch time, one exception is a Sample 2. In the case of Sample 3 lower scorch time value in comparison with Sample 1 and Sample 2 occured. Effect of altternative filler ENERGO is possible to observed on the value of scorch time. This effect can ascribe to content of $\mathrm{SO}_{4}{ }^{2-}$ in alternative filler ENERGO, which come into curing process and accelerate it. This effect is not very 
desirable in production of articles with complicated shape, when it is important for the blend to fill the mould perfectly. A positive effect on value of scorch time showed alternative filler GWI, which conversely increased the value of scorch time.

Optimum cure time $\left(\mathrm{t}_{\mathrm{C} 90}\right)$ is the time required for the torque to reach $90 \%$ of the maximum achievable torque $\left(\mathrm{t}_{\mathrm{C} 90}\right)$ relating to the time necessary to achieve optimal properties of the cured rubber [9].

In the case of values of optimal curing time it is possible observed the same effect as by scorch time values (increasing value of scorch time with decreasing content of ENERGO). It can be again seen effect of alternative filler ENERGO, which as stated earlier, come into curing process and accelerated it. Minimal value of optimal curing time showed the blend with the maximal content of alternative filler ENERGO. Reversely blend with lower content of alternative filler ENERGO and maximal content of GWI reached the highest value of optimal curing time. The slow down the vulcanization process can be attributed to the influence of the alternative filler from the glass production and its $\mathrm{pH}$ (higher $\mathrm{SiO}_{2}$ content) [10]. Too high value of optimal curing time is not very desirable, because it increases costs of curing process. From the point of view of the optimal curing time and scorch time, the optimal results (good value of scorch time and optimal curing time) showed blend with the composition according to Sample 2.

\subsection{Hardness results}

The hardness is the measurement of the penetration of an indentor in a sample under defined conditions. Rubber hardness is one of the most important properties for industrial application of rubber blends [11].

Table 3 Values of hardness of prepared vulcanizates

\begin{tabular}{|c|c|}
\hline Sample & Hardness value (IRHD) \\
\hline Sample 1 & $54.75 \pm 0.61$ \\
\hline Sample 2 & $56.75 \pm 0.61$ \\
\hline Sample 3 & $58.08 \pm 0.58$ \\
\hline Sample 4 & $58.33 \pm 0.61$ \\
\hline Sample 5 & $59.42 \pm 0.58$ \\
\hline
\end{tabular}

From the results of hardness measurement it can be seen, that highest value of hardness showed Sample 5 with the highest content of alternative filler GWI. With increasing the content of alternative filler from glass production GWI the values of hardness increased too. It is possible to assume, that alternative filler GWI have higher stiffening effect compared to alternative filler ENERGO. 


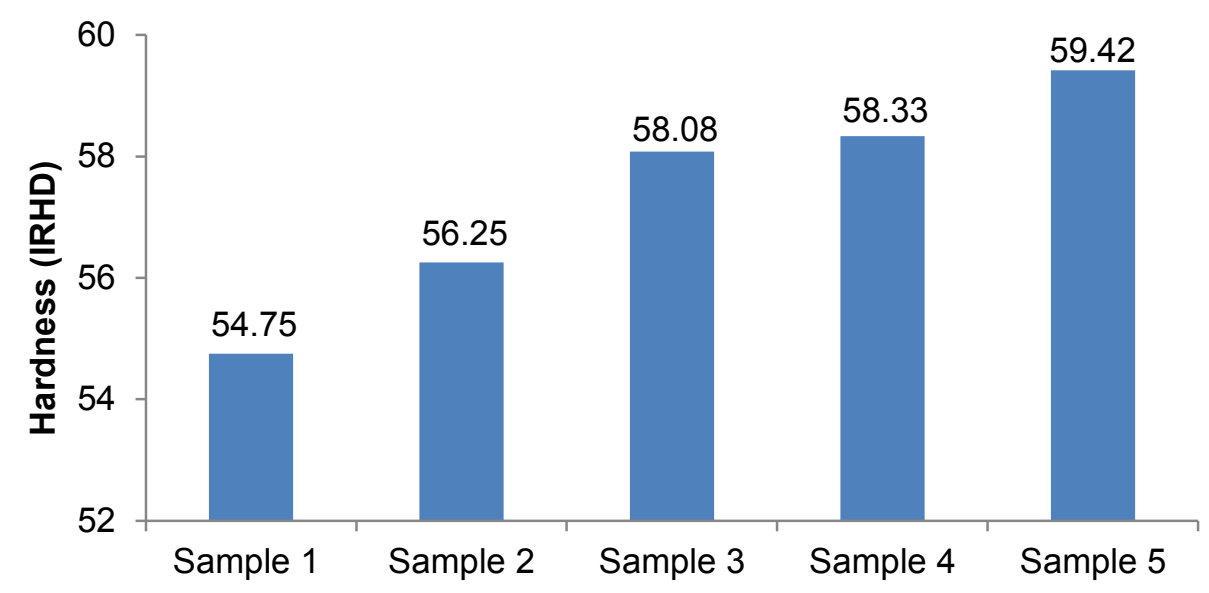

Fig. 3. Measured values of hardness (IRHD) of prepared vulcanizates

To confirm this trend, the Sample 5 may be mentioned, which contained the highest amount of alternative filler ENERGO and reached the lowest value of hardness. Although blends with high content of alternative filler GWI reached high value of hardness, but they were more brittle (cracking at bending). Higher amount of alternative filler GWI is only mechanically mixed into matrix network.

\subsection{Rebound resilience results}

Assessment of reflection elasticity is one of the best known methods to determine the rubber ability to absorb mechanical energy during impact [11].

Hardness and rebound resilience are two properties which often excluding (especially using carbon black).

Table 4 Values of rebound resilience of prepared vulcanizates

\begin{tabular}{|c|c|}
\hline Sample & Rebound resilience (\%) \\
\hline Sample 1 & $51.15 \pm 0.18$ \\
\hline Sample 2 & $50.43 \pm 0.12$ \\
\hline Sample 3 & $48.36 \pm 0.32$ \\
\hline Sample 4 & $46.05 \pm 0.10$ \\
\hline Sample 5 & $45.22 \pm 0.17$ \\
\hline
\end{tabular}




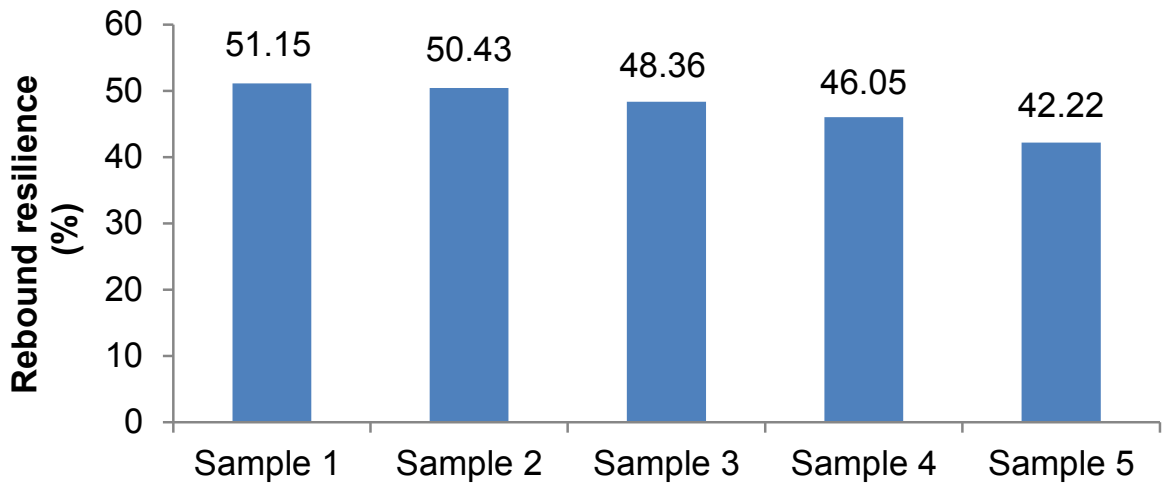

Fig. 4. Values of rebound resilience of vulcanizates

The highest value of rebound resilience showed Sample 1 which, of course, showed the lowest value of hardness. Sample 1 contained the highest amount of alternative filler ENERGO. Values of rebound resilience are also influenced by degree of crosslinking of rubber blend [12]. Because the alternative filler ENERGO come into curing process, it is possible to assume, that degree of crosslinking is higher. The lowest value of rebound resilience showed elastomer with the highest hardness value - Sample 5. Above-mentioned effect of high content of GWI (only mechanically mixed into matrix network) prevented higher deformation at pendulum crash, thereby decreased the value of rebound resilience.

\section{Conclusion}

The five elastomeric systems containing new alternative fillers based on two types the industrial wastes have been prepared. Results of the curing properties deterination showed, that alternative filler ENERGO from energetics is able to accelerate the curing process, and its content in rubber blends decreased scorch time, which may not be very desirable. Conversely the alternative filler GWI from glass production extended the scorch time. Both alternative fillers (GWI, ENERGO) showed significant effect on the values of hardness. Alternative filler from glass production caused higher stiffening effect compared to alternative filler ENERGO. Effect of alternative filler content in elastomeric vulcanizates also reflected on the values of rebound resilience. Influence of individual alternative fillers on the rebound resilience values was opposite in comparison with influence on the hardness values. As a target for the future may be to determine the degree of crosslinking and confirm the idea of influence of degree of crosslinking to rebound resilience value, when using the alternative filler ENERGO.

This work was supported by the projects: VEGA No. 1/0589/17, VEGA No. 1/0649/17, KEGA 008TnUAD-4/2017 and resulted from the project "Center for quality testing and diagnostics of materials", ITMS code 26210120046 relating to the Operational Program Research and Development funded from European Fund of Regional Development

\section{References}

1. E.P. Giannelis, Polymer layered silicate nanocomposites. Adv. Mater. 8, 29-35 (1996)

2. E.P. Giannelis, Polymer-layered silicate nanocomposites: synthesis, properties and applications. Appl. Organomet. Chem. 12, 675-680 (1998) 
3. J. S. Dick, Rubber Technology - Compounding and Testing for Performance (2nd Edition). chapter XXIII. Rubber Mixing, p. 504-522. (Munich: Hanser Publishers, 2009) ISBN-10: 1-56990-465-0

4. H.Norazlina, R. M. Firdaus, , W.M. Hafizuddin, Enhanced properties from mixing natural rubber with recycled polyvinyl chloride by melt blending. Journal of Mechanical Engineering and Sciences (JMES). 8, 1440-1447 (2015)

5. ISO 48, Determination of hardness

6. ISO 4662 Rubber, vulcanized or thermoplastic - Determination of rebound resilience

7. Matador Rubber, s.r.o., Rubber chemistry $2 \mathrm{cr}$ - Stages of vulcanization. (2007) $<$ https://www.tut.fi/ms/muo/vert/5_rubber_chemistry/>

8. J. S. Dick, Rubber Technology -Compounding and Testing for Performance (2nd Edition). p. 713-734. Munich:Hanser Publishers (2009). ISBN-10:1-56990-465-0

9. S. Raa Khimi, K. L. Pickering, A New Method to Predict Optimum Cure Time of Rubber Compound Using Dynamic Mechanical Analysis. Journal of Applied Polymer Science, Wiley Periodicals, Inc. (2013)

10. J. Malač, Gumárenská technologie [online], 1.vyd .Zlín (2005)

11. Matador Rubber, s.r.o., Test methods of rubber materials and product. (2007) $<$ https://www.tut.fi/ms/muo/vert/9_test_methods/>.

12. A. K. Bhowmick, M. L. Hall and H. A. Benarey, Eds., Rubber Products Manufacturing Technology. Marcel Dekker, Inc., New York (1994) 